\title{
Determination of fluid leakages in the different screw-retained implant-abutment connections in a mechanical artificial mouth
}

\author{
D. Martin-Gili ${ }^{1} \cdot$ M. Molmeneu ${ }^{2,3} \cdot$ M. Fernandez ${ }^{2,3} \cdot$ M. Punset ${ }^{2,3}$. \\ Ll. Giner ${ }^{1} \cdot$ J. Armengou ${ }^{4} \cdot$ F. Javier $\mathrm{Gil}^{2,3}$
}

\begin{abstract}
This study shows the potential risk of microfiltration between two different types of implant-abutment connections screwed at $45 \mathrm{Ncm}$ : external and internal. For the first time the use of a mechanical artificial mouth is used with the values (compression and torsion loads with a frequency of $2 \mathrm{~Hz}$ ) of the human chewing. The mechanical tests were performed with an artificial saliva at $37 \mathrm{oC}$. The microgap in the connection was measured by an Image Analysis software incorporated in a high resolution scanning electron microscopy. Implant connections were filled with methylene blue by using self-adjustable precision pipettes and the quantity of leakage was determined by high sensitivity spectometry. We showed that the internal connection has lower microgaps compared to the external ones and these microgaps increased with the number of mechanical cycles. The leakage of methylene blue was higher when the external connection was performed. Microgaps and the influence of the mechanical loads are very important for the long-term behavior avoiding the bacteria colonization in the dental implants. These aspects should be known by the implantologists.
\end{abstract}

1 Faculty of Dentistry, Universitat Internacional de Catalunya, Sant Cugat Campus, Barcelona, Spain

2 Biomaterials, Biomechanics and Tissue Engineering Group, Department Materials Science and Metallurgical Engineering, ETSEIB, Technical University of Catalonia (UPC), Av. Diagonal 647, 08028 Barcelona, Spain

3 Biomedical Research Networking Center in Bioengineering, Biomaterials and Nanomedicine (CIBER-BBN), Barcelona, Spain

4 School of Architecture, Universitat International de Catalunya, Barcelona Campus, Barcelona, Spain

\section{Introduction}

The purpose of dental implant rehabilitation requires more than its just successful osseointegration. An harmonious relationship between periimplant tissue levels and the existing dentition to achieve a functional and aesthetic restoration it is also necessary [1, 2]. This is accomplished with a careful balance of several parameters such as: the biocompatibility of the implant, the implant surface, the status of the recipient tissue, the surgical technique used for the prosthetic design and the type of load application [3].

Most dental implant systems consist of two main components: the endosteal part (the implant) and the transmucosal connection (the abutment). When the abutment is placed in its corresponding implant, a microgap is created in the interface abutment/implant (IAI) [4]. Further investigations evaluated that the oral microbiome can proliferate in this IAI microgap and affect all the peri-implant tissues [5-10]. It is widely known that bacterial leakage could cause an inflammatory process in the peri-implant tissues near the level of the alveolar bone [11, 12].

The usual classification of connections divides them into two main groups: the external and internal types. Implant design is a critical variable in the microfiltration of the connection. It is important to study the type of connection in order to reduce microfiltrations between implant and abutment as well as to minimize bacterial colonization of the implant.

However, not all the implant connection designs have similar behavior in studies that compare microfiltration [4, 13-18] or changes at bone level [19, 20]. For this reason, it is important to study the type of connection in order to reduce microfiltration between implant and abutment under mastication conditions. 
Several studies have been conducted in order to quantify the microfiltration between the implant and the abutment and some of these studies published that evaluated microfiltration were performed with bacterial cultures only under unloaded conditions, because of the difficulties with handling and culturing [17]. Several studies also reported the possibility that their results were false negative or false positive [13, 16, 21].

The aim of the present study is to show the potential risk of microfiltration between two different types of implantabutment connections using a novel dynamic-loading model in vitro that mimics the human mastication.

\section{Materials and methods}

\subsection{Materials}

Two different designs of implant systems were tested, using 20 samples of SK2 Klockner ${ }^{\circledR}$ Implant system (Klockner $^{\circledR}$, Barcelona) as external connection and 20 samples of ESSENTIAL CONE Klockner ${ }^{\circledR}$ implant system as internal connection. Commercially packaged implants and abutments were used. Both systems are very similar to other dental implants existing in the market and the results can be easily generalized. Figure 1 shows both implants studied.

In both systems the torque to tighten the abutment screw of single crown abutments was $45 \mathrm{Ncm}$, leading to better force-fit. Forty dental implants for each connection type were studied. One subgroup $(n=5)$ was used to observe and evaluate the microgap before and after load cycling and other ( $n=15)$ was used to evaluate the dynamics of loading for each connection.

Methylene blue (Sigma-Aldrich, USA) was used as a dye to determine the grade of filtration to the media and the average released rate. Cold mounting epoxy-type resin was used for embedding the implant samples according to UNE-EN-ISO 14801 standard specifications). Hydrophilic silicone pellet type 3 ISO 4823 was used to remove any traces of dye within abutment connection. Zinc oxide eugenol cement (Temp Bond) was employed to assure a correct dye measurement.

\subsection{Dye preparation}

After a careful bibliographic research, methylene blue was chosen for presenting an absorption spectra of $660 \mathrm{~nm}$ with a sharp and defined peak that increased the identification accuracy for early detection. These characteristics agree with the light absorption needed for our study as previously published on the Sigma-Aldrich ${ }^{\circledR}$ Handbook of stains, dyes and indicators.

\subsection{Preparation of the model}

Implants were embedded perpendicularly in an auto-curing resin according to the specifications detailed in UNE-ENISO 14801 standards. Implants were mounted into resin to mimic oral conditions, where the bone may absorb some forces transmitted to the implant-abutment screw connection. Figure 2a shows the structure of the experimental model. The elastic modulus of the resin used had to be higher or equal to $3 \mathrm{GPa}$. Moreover, the implant was placed $3 \mathrm{~mm}$ above the resin, $3 \mathrm{~mm}$ simulating bone reabsorption. It was also placed at an angle of 30o from the axis of compression-torsion machine, all as indicated by the UNEEN-ISO 14801 standards.

Implant connection was filled with methylene blue by using self-adjustable precision pipettes. The dye dilution was prepared using 4 grams of dye dissolved in $100 \mathrm{ml}$ of distilled water, and a solution 1:4 was used (Fig. 2b). Each implant was filled to maximum capacity according to internal dimensions of the interconnection design to avoid and minimize the presence of air entrapped between inner dye solution and outer artificial saliva media, introducing $6 \mathrm{ll}$ in the internal connection implant system and $9 \mathrm{ll}$ in external connection implant system. Internal volume
Fig. 1 a Implant-abutment with external connection prepared previous valuation in SEM. b Implant-abutment with internal connection prepared previous valuation in SEM
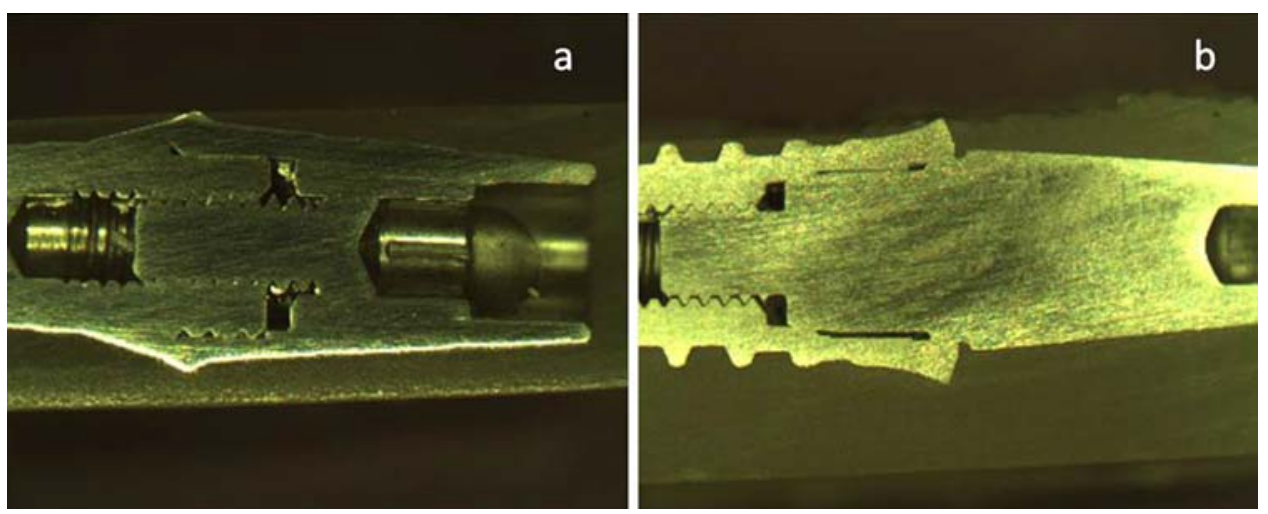

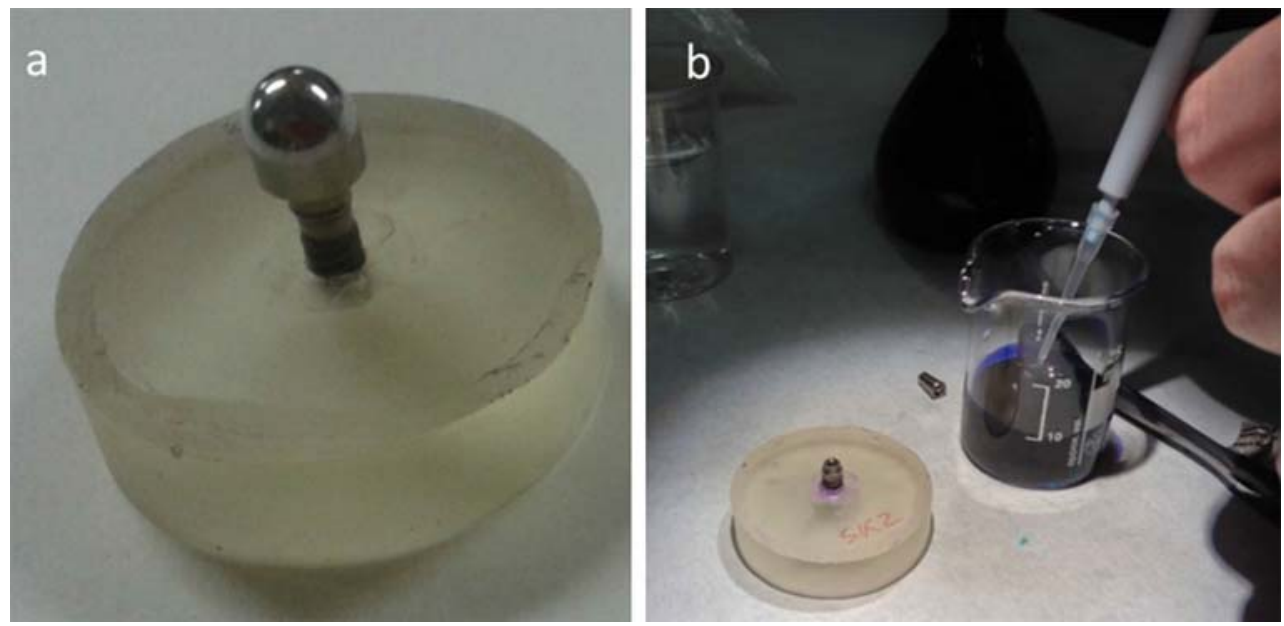

Fig. 2 a Polimerized sample following the international standard ISO-14801. b Methylene blue dye introduction (Color figure online)

capacity of each implant system evaluated was measured according to specifications of implant manufacturer.

Once filled with a uniform amount of methylene blue dye, the implant was embedded, the abutment-crown combination was assembled at $45 \mathrm{Ncm}$ to the implant with an abutment screw following manufacturer's surgical protocols.

In order to remove any traces of dye within abutment connection and to avoid false measurements, an hydrophilic silicone pellet type 3 ISO 4823 was introduced inside the upper end of the abutment component. Then the hemispherical loading member was cemented with zinc oxide eugenol cement (Temp Bond), assuring the correct dye measurement and emulating the real clinical conditions currently used in dental procedures and surgical protocols.

Simultaneous characterization of the mechanical behaviour and leakage characterization were realised.

Mechanical behavior of samples was performed following the international standard ISO-14801 "Fatigue test for endosseous dental implants." Mechanical tests were performed using a universal testing machine tensioncompression-torsion fatigue model MTS Bionix 370 (MTS-USA) designed to work on biomaterials. A $25 \mathrm{kN}$ load cell was used and it was equipped with a PC connection and a software package TestStar II model control. Special clamps were manufactured in order to facilitate the samples extraction without stopping the equipment.

A compressive force of $700 \mathrm{~N}$ and torsion of 30 was applied for a total of 100,000 cycles at $2 \mathrm{~Hz}$ of load frequency at $37 \mathrm{oC}$. These conditions are very similar to the human mouth. A chamber was filled with $100 \mathrm{ml}$ of artificial saliva until the specimens were totally immersed to imitate wet oral conditions [13, 15, 18, 21, 22]. The chemical composition of the artificial saliva is shown in Table 1.
Table 1 Chemical composition of the artificial saliva

\begin{tabular}{ll}
\hline Chemical product & Composition $\left(\mathrm{g} / \mathrm{dm}^{3}\right)$ \\
\hline $\mathrm{K}_{2} \mathrm{HPO}_{4}$ & 0.20 \\
$\mathrm{KCI}$ & 1.20 \\
$\mathrm{KSCN}$ & 0.33 \\
$\mathrm{Na}_{2} \mathrm{HPO}_{4}$ & 0.26 \\
$\mathrm{NaCl}$ & 0.70 \\
$\mathrm{NaHCO}_{3}$ & 1.50 \\
Urea & 1.50 \\
Lactic acid & up to $\mathrm{pH} 6.7$
\end{tabular}

Then a cyclic fatigue load was applied to each abutmentimplant system. Figure 3 illustrates how the test was setup.

Aliquots of $1 \mathrm{ml}$ of media were sequentially taken off after six different times (1, 2, 4, 6, 8 and 24 h) in order to determine the dye dissolution rate in the medium.

Samples taken at different times of testing were stored in polymeric eppendorfs in order to avoid contamination concerns. Moreover, in order to prevent evaporation and concentration of the dye in the medium, once the samples were taken and placed in eppendorfs, they were stored in the refrigerator.

Measurements were taken at the maximum wavelength of absorption of the dye (660 nm), and calibration curves were performed in order to have well defined sensing range of methylene blue with the detection equipment used. The dye concentration released to the media from the implants was objectively quantified using a microplate spectrophotometer (Tecan ${ }^{\circledR}$, Switzerland).

Measurements made by the spectrophotometer provided data in absorbance units [OD], which required the realization of a standard curve of the dye at different concentrations in 


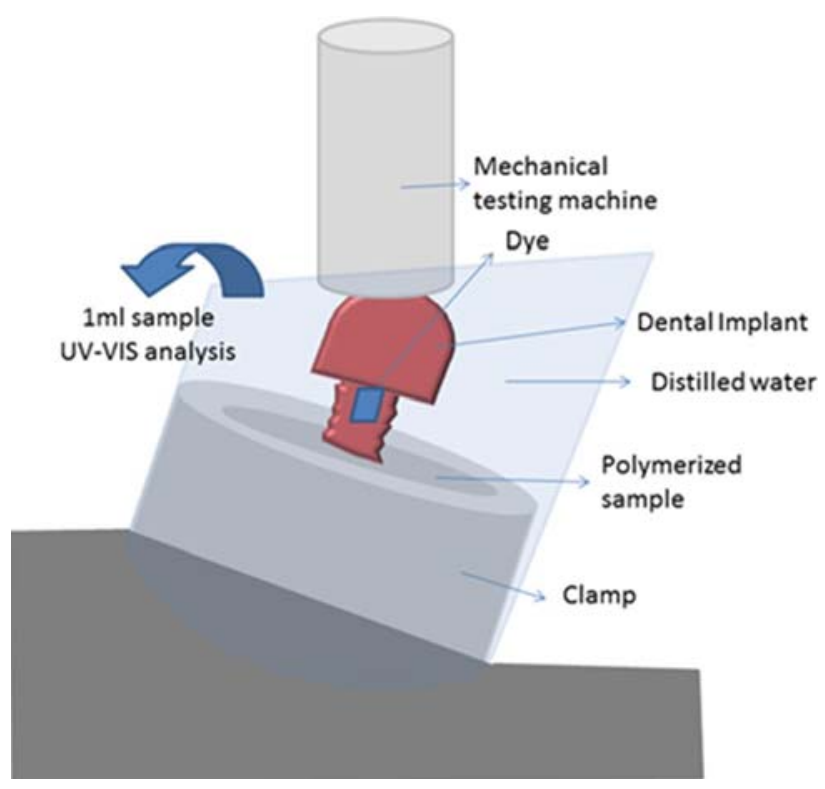

Fig. 3 Dynamic-loading experimental operation scheme for infiltration measurement

order to obtain data in units of concentration of dye released in distilled water curve $(\mathrm{g} / \mathrm{ml})$.

Simultaneously, we performed a control group with three samples of each connection. The measurement methodology was equal to that used in the samples of the group with cyclic load but obviously without the application of any load. Samples were then left in suspension with $100 \mathrm{ml}$ of artificial saliva during $24 \mathrm{~h}$ and measurements were taken in the same intervals as the samples of the group with cyclic load.

\subsection{Observation of the microgap with a high resolution scanning electron microscope}

A scanning electron microscope (Neon40 with GEMINI column) was used for the implant-abutment microgap observation under conditions of $20 \mathrm{kV}$ potential. One subgroup $(n=5)$ was used to observe and evaluate the microgap before and after load cycling. All samples (implant-pillar) were embedded in a resin glycolmethacrylate (Heraeus Kulzer ${ }^{\circledR}$, Germany) and after polymerization, each sample was cut along its longitudinal axis with a diamond wheel of high precision machine Strauen Minitorm $^{\circledR}$. We then proceeded to assess the internal vertical marginal microgap.

\subsection{Statistical analysis}

A statistical analysis using the Minitab $1.2 .0^{\circledR}$ was performed. Data was analyzed by Student's t test with a confidence interval of $95 \%$. For the description of the data, mean values and standard deviations (SD) were calculated. A P B 0.05 was considered statically significant.

\section{Results}

The gaps measured are presented in Table 2 for each connection. In some cases, we found excellent adaptation between implant and screw-retained abutment, being the distance lower than the a normal bacteria diameter and consequently there were not a possibility of an infiltration with microorganisms.

The internal connection implants presented lower microgaps than the external ones, $\mathrm{P}$ value of 0.01 , with statistical significance. An example for each connection type of the microgap is showed in Fig. 4 before and after load cycling. An increase of the microgap is observed as the number of cycles increases due to the micromovements producing permanent deformation in the titanium.

An image of the microfiltration of the samples is showed in Fig. 5. Statistically significant differences between the two groups of samples tested (external and internal connections) were observed with a $\mathrm{P}$ value of 0.01 and a confidence interval of $95 \%$.

Alongside performing microfiltration tests-masticatory fatigue under dynamic loading, static infiltration studies were also carried out under no load conditions, in order to assess the level of tightness of the implant-abutment joint in unloaded state assembly.

\section{Discussion}

For the first time, we have shown a novel study measuring in vitro microfiltrations under loaded conditions and evaluation without bacteria in a model that resembles human conditions (compressive-torsion).

Different studies have previously demonstrated the importance of studying the microfiltration of IAI under loaded conditions [4, 15, 17, 23]. Chewing forces in the prosthetic

Table 2 Measurements of the microgap for internal and external connections

\begin{tabular}{ll}
\hline Type of connection & Microgap (lm) \\
\hline Internal before mechanical cycles & $1.86(0.19)$ \\
Internal after mechanical cycles & $2.34(0.57)$ \\
External before mechanical cycles & $2.53(0.25)$ \\
External after mechanical cycles & $4.01(0.78)$ \\
\hline
\end{tabular}

Each type of connection was measured in 5 different implants, the total measures for each connection was 350 . The result is the average of all measurements. The results present statistically differences with $\mathrm{P} \backslash 0.01$ 

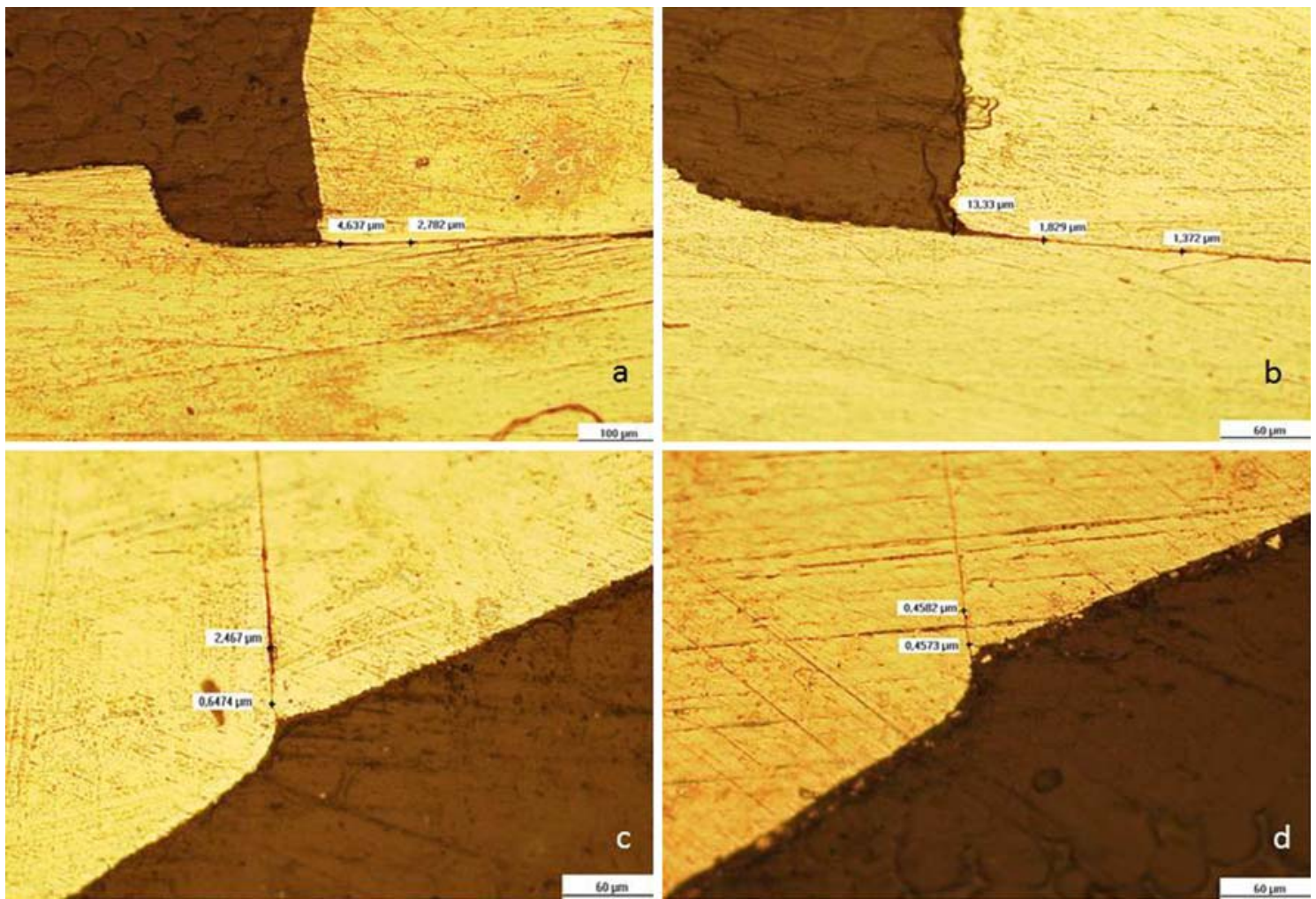

Fig. 4 Observation by microscope with image analysis the microgap of two types of connections. a External connection before mechanical

c Internal connection before mechanical cycles. d Internal after 100,000 mechanical cycles

Fig. 5 Blue methylene concentration release versus time (Color figure online)

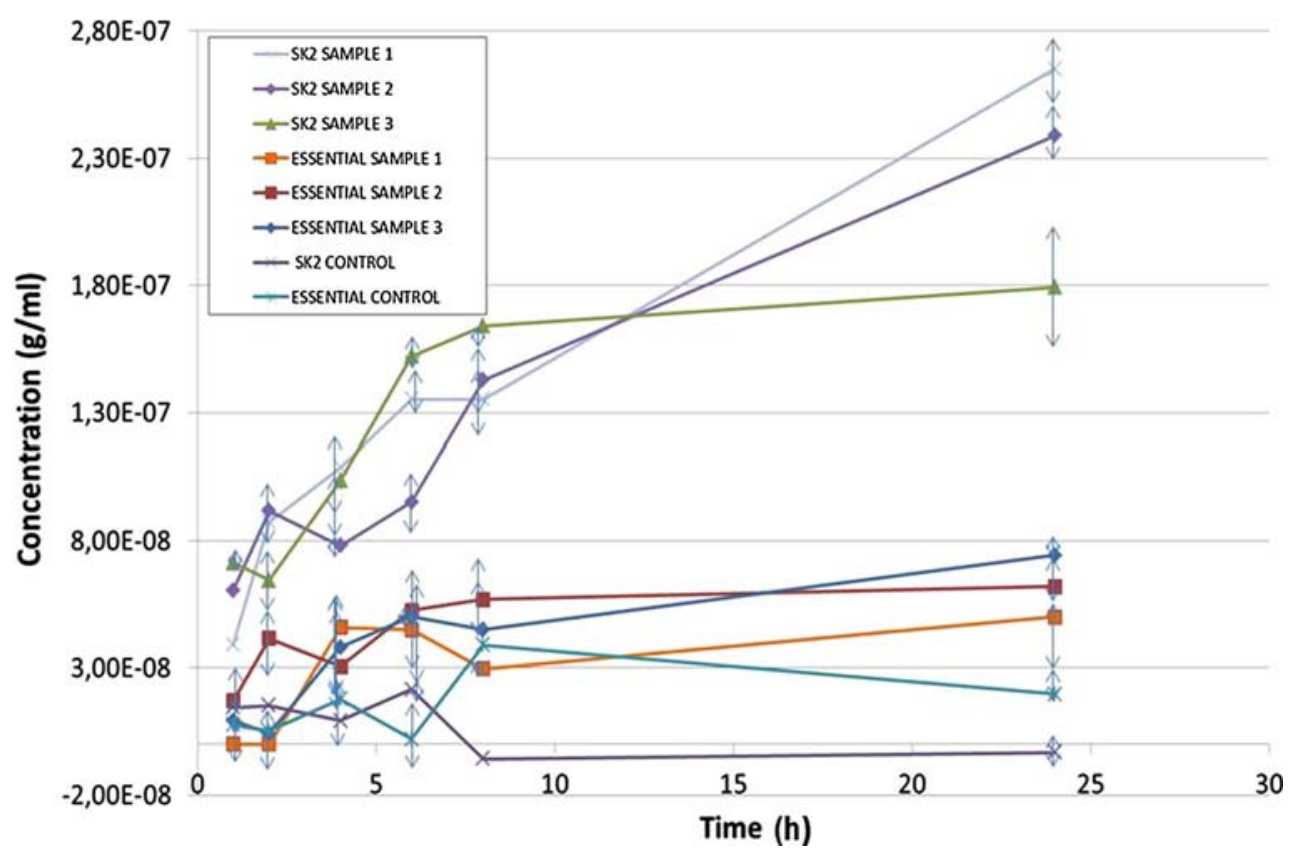

restoration produces micromovements at IAI resulting in an increase of the microgaps between the implant and the abutment [4, 24, 25]. Microgaps increases the oral opening and closure causing a pump effect into the IAI that facilitates bacterial colonization of the inner empty space of device [24]. 
Although there are some studies of bacterial microfiltration in implants, none of them have used any kind of dye to evaluate the leakage under loaded conditions. Most of these studies of microfiltration are under unloaded conditions and bacterial culture was used [1-8]. Jansen VK et al. [16] and Jawarosky ME et al. [18] demonstrated the presence of microfiltration in external connections by E. coli inoculation in a comparative study of internal and external connections. Other studies showed that microfiltration with A. actynomycetemcomitans [13, 21, 26] was observed in different internal connections. Although the implant connection microfiltration using bacterial cultures is the most widely accepted technique, false negative or false positive results have been reported [16, 21].

In the present study, a dye was used in order to minimize the possibility of false positive or false negative signal as well as to facilitate an real objective measurement.

But our study is not the first one to use dye in its methodology, Coelho PG et al. in 2008, in a comparative microfiltration study between different connections used blue toluidine [27]. In that paper, blue toluidine was introduced inside connection, submerged in distilled water and evaluated by sampling the distilled water with spectrophotometric analysis at different times. We decided to use methylene blue because of its high color intensity, as well as in terms of high solubility and narrow peak signal obtained by spectrophotometry. Others experience as Gross $\mathrm{M}$ et al. used a colored marker to assess the soundness of the connections and they applied a pressure of $2 \mathrm{~atm}$ on the connection [22].

In the present study, as previously shown in the paper by Coelho PG. et al. [27], a dye was introduced in the connection with the objective of simulating the bacterial microfiltration. The dye placement is justified within the connection, because bidirectional fluid leakage and bacterial penetration by IAI have been demonstrated in in vitro studies $[8,9,16]$. Although the methodology was similar, we performed the experiment under cycling loaded conditions to emulate the correct natural masticatory functioning.

This load level of $700 \mathrm{~N}$ was chosen from several previous pilot studies where a compromise between the load and the release of the dye connection was studied. It was also selected as an average value between the maximum load achieved by molar teeth in men (847 N) and in women (595 N) [26]. Level loading frequency was performed at $2 \mathrm{~Hz}$ under wet conditions according to ISO-14801:2008 standard "Fatigue test for endosseous dental implants specifications". Statistically significant differences between the two groups of samples tested (internal and external connections) were observed. Microfiltration and microgap measurements were lower in the internal connection than in the external connections samples. Our study agrees to what was previously reported for the internal connections [13, 16, 18]. Do Nascimento C et al. [17] showed in their study that microfiltration with human saliva with and without cyclic loading exhibit greater bacterial filtration. They concluded that, under loaded conditions, bacterial presence was increased in all samples and that internal connection showed less bacterial presence under loaded and unloaded conditions.

\section{Conclusion}

The internal connection had a smaller microgap than the external ones with significant statistical differences. Very good adaptation between the implant and the screw-retained abutment were observed, in many cases the distances were smaller than the bacteria diameter and consequently is not possible an infiltration of microorganisms. The fatigue behavior of the external hexagon interface presented superior result compared to the internal hexagon interfaces. Using a new model that resembles the human mastication, we proved that in a novel in vitro model, that internal connection implants had smaller microgaps and lower microfiltration compared to the ones with external connection. A novel in vitro experimental protocol was able to assess the potential risk of microfiltration of IAI in different implant designs under dynamic loading conditions.

Acknowledgments This work was supported by CICYT Spanish project MAT-2012-30706 and the Andorra and Catalan Government for CTP grants. The authors are grateful to Soadco ${ }^{\circledR}$ for your support.

Compliance with Ethical Standards

Conflict of interest The authors have not financial relationship with the organization that sponsored the research. The authors have full control of all primary data and that they agree to allow the journal to review their data if requested.

\section{References}

1. Wagenberg B, Froum SJ. Prospective study of 94 platformswitched implants observed from 1992 to 2006. Int J Periodontics Restor Dent. 2010;30:9-17.

2. Tarnow DP, Cho SC, Wallace SS. The effect of inter-implant distance on the height of the inter-implant bone crest. J Periodontol. 2000;71:546-9.

3. Albrektsson T, Brånemark PI, Hansson HA, Lindström J. Acta Orthop Scand. 1981;52:155-70.

4. Steinebrunner L, Wolfart S, Bossmann K, Kern M. In vitro evaluation of bacterial leakage along the internal implant-34 abutment interface implant-abutment interface of different implant systems. Int J Oral Maxillofac Implants. 2005;20:875-81.

5. Quirynen M, Bollen CM, Eyssen H, van Steenberghe D. Microbial penetration along the implant components of the Brånemark system. An in vitro study. Clin Oral Implants Res. 1994;5(4): 239-44. 
6. Broggini N, Mcmanus LM, Hermann JS. Persistent acute inflamation at the implant-abutment interface. J Dent Res. 2003;82:232-7.

7. Adell R, Lekholm U, Rockler B, Brånemark P-J. A 15-year study of osseintegrated implants in the treatment of the edentulous jaw. Int J Oral Surg. 1981;10:387-416.

8. Quirynen M, van Steenberghe D. Bacterial colonization of the internal part of two -stage implants. An in vitro study. Clin Oral Implants Res. 1993;4:158-61.

9. Traversy MC, Birek P. Fluid and microbial leakage of implant abutment assembly in vitro. J Dent Res. 1992;71:754.

10. Ericsson I, Persson LG, Berglundh T, Marinello CP, Lindhe J, Kinge B. Different types of inflamatory reactions in periimplant soft tissues. J Clin Periodontol. 1995;22:255-61.

11. Broggini N, McManus LM, Hermann JS. Periimplant inflamation defined by the implant-abutment interface. J Dent Res. 2006;85: 473-8.

12. Hermann JS, Schoolfied JD, Schenk RK, Buser D, Cochran DL. Influence of the size of the microgap on crestal bone changes around titanium implants. A histometric evaluation of unloaded non-submerged implants in the canine mandible. J Periodontol. 2001;72:1372-83.

13. Tesmer M, Wallet S, Koutouzis T, Lundgren T. Bacterial colonization of the dental implant fixture-abutment interface: an in vitro study. J Periodontol. 2009;80(12):1991-7.

14. Texeira W, Ribeiro RF, Sato S, Pedrazzi V. Microleakage into and from two-stage implants: an in vitro comparative study. Int J Oral Maxillofac Implants. 2011;26:56-62.

15. Koutouzis T, Wallet S, Calderon N, Lundgren T. Bacterial colonization of the implant-abutment interface using an in vitro dynamic loading model. J Periodontol. 2011;82(4):613-8.

16. Volker K, Jansen J. Microbial leakage and marginal fit of the implant- abutment interface. Int J Maxillofac Implants. 1997;12: 527-40.

17. Do Nascimento C, Miani PK, Pedrazzi V, Gonçalves RB, Ribeiro RF, Faria AC, Macedo AP, de Albuquerque RF Jr. Leakage of saliva through the implant-abutment interface: in vitro evaluation of three different implant connections under unloaded and loaded conditions. Int J Oral Maxillofac Implants. 2012;27(3):551-60.

18. Jaworski ME, Melo AC, Picheth CM, Sartori IA. Analysis of the bacterial seal at the implant-abutment interface in externalhexagon and morse taper-connection implants: an in vitro study using a new methodology. Int J Oral Maxillofac Implants. 2012;27(5):1091-5.

19. Berglundh T, Abrahamsson I, Lindhe J. Bone reactions to longstanding functional load at implants: an experimental study in dogs. J Clin Periodontol. 2005;32:925-32.

20. Laurell L, Lundgren D. Marginal bone level changes at dental implants after 5 years in function: a meta-analysis. Clin Impl Dent Relat Res. 2011;13:19-28.

21. Aloise JP, Curcio R, Laporta MZ, Rossi L, da Silva AM, Rapoport A. Microbial leakage throught the implant- abutment interface of Morse taper implants in vitro. Clin Oral Implants Res. 2010;21:328-35.

22. Gross M, Abramovich I, Weiss EI. Microleakage at the abutmentimplant interface of osseointegrated implants: a comparative study. Int J Oral Maxillofac Implants. 1999;14:94.

23. Binon PP. The effect of implant/abutment hexagonal misfit on screw joint stability. Int J Prosthodont. 1996;9:149-60.

24. Ranger B, Gunne J, Sullivan DY. Mechanical aspects of a Bränemark implant connected to a natural tooth: an in vitro study. Int J Oral Maxillofac Implants. 1991;6:177-86.

25. Zipprich H, Weigl P, Lange B, Lauer H-C. Micromovements at the implant-abutment interface: measurement, causes and consequences (in German). Implantologie. 2007;15:31-45.

26. Assenza B, Tripodi D, Scarano A, Perrotti V, Piattelli A, Iezzi G, D'Ercole S. Bacterial leakage in implants with different implantabutment connections: an in vitro study. J Periodontol. 2012;83(4):491-7.

27. Coelho PG, Sudack P, Suzuki M, Kurtz KS, Romanos GE, Silva NR. In vitro evaluation of the implant abutment connection sealing capability of different implant systems. J Oral Rehabil. 2008;35(12):917-24. 